\title{
Causes, Nature and Effects of Variations in Highways
}

\author{
T.H.S. Priyantha, Gayani Karunasena and V.A.K. Rodrigo
}

\begin{abstract}
Highways play a significant role in the economic growth of developing countries. Sri Lankan government also has realized such importance and has directed special focus on constructing new highways. However, highways construction is not a simple task and these projects are often typified by risk and complexities which create a range of problems that has to be dealt with utmost care. Variations are one of them, which commonly occur due to uncertain scopes of work defined at the beginning. Thus, this study is undertaken to identify causes, nature and effects of variations in highways construction in Sri Lanka. A questionnaire survey was undertaken to identify frequent causes of variations and semi-structured interviews were conducted to capture data regarding nature and effects of variations. The results revealed that change in mind force and requirement increases were the main causes of client originated variations while design changes and defects in BOQ were the main causes of consultant originated variations. Land acquisition and funds arranging issues were identified as main unforeseeable cause that originates variations. The study further revealed that omission of any work has a significant impact on the nature of variations. In most situations, variations have resulted in cost overruns with an average increase of $9.9 \%$ of the initial contract sum.
\end{abstract}

Keywords: Causes of variations, Nature of variations, Effects of variations, Highway construction, Sri Lanka

\section{Introduction}

Highways make possible the rapid, flexible and relatively inexpensive movement of persons and freight between cities and throughout the countryside (Gessaman and Sisler 1976 cited Day, 2006). Road Development Authority (RDA) of Sri Lanka has categorized highways into two major sections. Highways which join two towns or cities in two separate provinces are categorised as of Grade $A$ and those joining two towns within a province are categorised as of Grade B. The total road length in Sri Lanka is $91,907 \mathrm{~km}$, of which the total highway length is approximately about up to $11,696 \mathrm{~km}$ (RDA, 2009).

Any construction including highways compromise with various kinds of challenges such as natural disasters, accidents in construction, disputes, cost and time overruns due to variations, material wastage etc. Among those, Latham (1993) highlights variations as potentially a major source of disputes in highways construction and often have a disastrous impact on a project's performance. Akinsola and Potts (1998) further highlight variations as a critical issue with reference to claims and disputes caused by variations. Nishanth (2005) indicates that this results in cost and time overruns in road projects. According to Bogamuwa (2006), variations cause about $13 \%$ increase over the initial contract sum in road projects in Sri Lanka. Thus, it is significant to study about variations in highways and their impacts. In this context, this paper presents the outcomes of a study conducted on highways in Sri Lanka regarding causes, nature and effects of variations and perceptions of contracting parties in highways regarding variations. Next section provides an overview on highways of Sri Lanka.

\section{Literature review}

\subsection{Highways in Sri Lanka}

Highways are on which private automobiles, trucks, buses, etc., travel on and a large portion of public transportation provided certain facilities that private entities can not provide (Oglesby and Hicks, 1982). The motive of expenditure incurred on highways and public transportation is to raise the level of entire economy by providing easy access to work places and transportation of goods; to assist in problems of national defence; to make easier the provision of community services such as police and fire protection, medical care, schooling, and delivery of mails; and to open more opportunities for recreation and travel (Oglesby and Hicks, 1982). In addition, certain improvements to highways benefit motor-vehicle users through reduced costs of vehicle operation, savings in time, reduction in accidents and increased comfort and ease of travel.

The Sri Lankan road network has been developed by number of public authorities. Public Works Department was the first Sri Lankan road authority involved with developing the road network. In 1969, a major policy change was made and a new Department of Highways was formed for development and maintenance of all classes of roads categorised as A, B, C, D, E. (RDA, 2006). In 1983 the Road Development Authority (RDA) was incorporated under Ministry of Highways by Road Development Authority Act No 73 of 1981 and its functions at inception were confined to execution of selected construction works (RDA, 2006). The functions of RDA were expanded in 1986 to encompass the responsibility of developing and 
maintaining all classes of roads in the country $(A, B$, C, D and E class roads) (RDA, 2006). In 1989 with the devolution of power to provincial councils by the 13th amendment to the constitution, roads classified under $C, D$ and $E$ classes were assigned to provincial councils and RDA was exclusively delegated with the responsibility of development and maintenance of national highways, categorised as class $A$ and $B$ roads. Accordingly, in Sri Lanka the term 'highway' is used to designate major roads which are available for public purposes under classes A and B (RDA, 2009).

As previously mentioned, highways construction faces different kinds of problems such as accidents, construction disputes, time and costs overruns and material wastage. Accidents frequently occur in highways construction due to lack of care in operating plants and machineries. In spite of that, cost and time overruns related disputes have become widespread mainly caused by variations (Lathem 1993; Akinsola and Potts, 1998). Thus, it can be argued that variations as one major source of disputes in highways construction as well.

\subsection{Variations in highways}

The word 'variations' in construction is generally employed in two senses. Firstly, it means an alternation whether by addition or omission to physical work content and secondly, the word may denote a change in the contractual terms upon which the relevant work is to be performed (Dorter, 1991). According to Akinsola and Potts (1998, p.1), "a variation in this sense is described as the extent to which the contract is varied between the time at which it is let and the issue of the certificate of practical completion". By considering aforesaid definitions, the term "variation" can be simply identified as an instrument that "varies the work in the construction". As Potts (2003) discussed, variations are inevitable on building and civil engineering projects and may range from small changes having little consequential effects to major revisions, which result in considerable delay, and/or disruptions to a project. As claims and conflicts in construction have become endemic and those are especially caused by variations (Akinsola and Potts, 1998) lack of effort in managing these conflicts can result in disputes (Fenn et al, 1997). Consequently, it is apparent that highways also face this problem as a civil engineering project.

In Sri Lanka, parties involved in highways construction generally adopt two types of standard forms of conditions of contract. Most government funded projects use ICTAD 2007 standard bidding document for major contracts, commonly referred to as SBD 2, and foreign funded projects use FIDIC 1999 conditions of contracts, called the Red Book. According to both of those documents "variation means any change to the works, which is instructed or approved as a variation under clause 13 [Variations and Adjustments]" (ICTAD 2007; FIDIC 1999). Accordingly the term "variation" can be simply identified as an instrument that "varies the work in the construction".

According to Arseculeratne (1992) some variations may result in genuine change of circumstances and others from the design team's own inadequacy. Ivor (1993) indicates that the engineer has an authority to vary any part of the works which includes variations as changes in specified sequence, method or timing of construction. It is further indicated that, a contractor should not go ahead with any variation order or instruction unless received as written order or written confirmation of a verbal order from the engineer.

When handling variations, there is a specific procedure to follow and it depends on the standard conditions of contract selected for a project. However, literature revealed that following tasks are common in most contract documents which should be fulfilled to succeed in variation procedure under any conditions of contract. They are,

\section{- Measuring Variatio \\ - Valuing Variation}

Variation measurement can be done from drawings or, if not available, by physically measuring substituted work on site after it has been carried out (Ramus, 1989). This same procedure will be necessary whether the contract is based on a bill of firm quantities or on specification and drawings only. In the case of contracts based upon bills of approximate quantities and those based on a schedule of rates, the whole of works will have to be measured as described above (Ramus, 1989).

There are several ways of valuing variations, the choice in a particular case being that which is appropriate to the circumstances (Ramus, 1989). However, establishing a realistic valuation for variations on construction works is often not an easy task. Both parties will need considerable experience and sound judgment to settle variations. The parties are required to have a sound appreciation of methods of construction, estimating practices, contractual and legal implications and construction programming techniques including use of planning software (Potts, 2003; Sutrisna et al, 2003; Sutrisna and Potts 2004). Next section explains the causes for variations in highways construction.

\subsubsection{Causes for variations}

Many scholars discuss various causes for variations in roads construction, mainly categorised under following three sources of origin as illustrated in table 01. Huiwu et al (2003) and Nishanth (2005) mainly 
discuss variations originated by the client and consultant. Wickramasinghe (2006) highlights causes of variations generated by consultant specifically design changes and defects in design. Nishanth (2005) adds more details on variations originated by enforceable events. Accordingly, sources and relevant causes for variations can be illustrated as follows.

Table 1: Causes of variations in road construction

\begin{tabular}{|l|l|}
\hline Source of Variation & Cause of Variation \\
\hline \multirow{4}{*}{$\begin{array}{l}\text { Originated by Client } \\
\text { Huiwu et al, 2003; Nishanth, 2005) }\end{array}$} & Requirement increases \\
\cline { 2 - 2 } & Change in mind- choice \\
\cline { 2 - 2 } & Change in mind-forced \\
\cline { 2 - 2 } & Poor / vague brief by client \\
\cline { 2 - 2 } & $\begin{array}{l}\text { Inadequate time provision to prepare tender } \\
\text { documents }\end{array}$ \\
\hline $\begin{array}{l}\text { Originated by Consultant } \\
\text { Wuiwu et al, 2003; Nishanth, 2005; } ;\end{array}$ & Design changes \\
\cline { 2 - 2 } & Defects in design \\
\cline { 2 - 2 } & Inadequate consideration of design \\
\cline { 2 - 2 } & Incorrect assessment of brief \\
\cline { 2 - 2 } & Defects in BOQ \\
\cline { 2 - 2 } & Improper specifications \\
\cline { 2 - 2 } & Shortcomings in contractual pricing documents \\
\cline { 2 - 2 } & Inadequate site investigation \\
\hline $\begin{array}{l}\text { Originated by Unforeseeable Events } \\
\text { (Nishanth, 2005) }\end{array}$ & Restrictions due to existing utility lines \\
\cline { 2 - 2 } & Floods and landslides \\
\hline
\end{tabular}

Next section explains the research methodology adopted for collection of empirical data of the study concerned.

\section{Methodology}

Three modes of data collection techniques were used to gather data for the study concerned. First, a questionnaire survey was conducted to identify frequent causes for variations in highway projects. Construction professionals involved in highway projects were selected based on the convince sample method. Profile of questionnaire sample is illustrated in table 2.

Table 2: Profile of sample

\begin{tabular}{|l|l|l|}
\hline Category & Number & Response (\%) \\
\hline M1 for Roads & 25 & $81 \%$ \\
\hline RDA & 6 & $19 \%$ \\
\hline
\end{tabular}

Questionnaire was prepared with use of simple ordinal scale representing four scales as, often, sometimes, rarely and not relevant. Median answers of respondents were taken in to account to analyse the questionnaire as to get the view of "the middle man" who is not biased to any of the extremes.
Secondly, semi structured interviews were conducted with 10 professionals involved in highways construction, numbering 8 from grade M1 contractors and 2 from RDA to identify nature and effects of variations and to evaluate perceptions of contracting parties on variations. Interview transcripts were prepared using interviews data and analysed by using software called "NUDIST VIVO." Coding structure developed for the analysis of data is illustrated at section 4.2 of this paper.

Third stage involved collection of data on variations to identify nature of variations noted in highway projects during past few years. A sample of 58 final accounts of RDA road projects distributed among the nine provinces were selected and analysed by using $t$ test and sample mean. SPSS statistical software was used to assist the analysis. Next section explains the survey findings of the study.

\section{Survey findings}

This section discusses and interprets results of the study. Initially the results of questionnaire survey is presented on causes for issuing variations under three originating sources as client originated, consultant originated and unforeseeable events as illustrated in table 2. 
Table 2: Causes for issuing variations

\begin{tabular}{|c|c|c|}
\hline $\begin{array}{l}\text { Source } \\
\text { origination }\end{array}$ & Cause of Variation & Occurrence \\
\hline \multirow{5}{*}{$\begin{array}{l}\text { Originated by } \\
\text { Client }\end{array}$} & Requirement increases & Often \\
\hline & Change in mind- choice & Rarely \\
\hline & Change in mind-forced & Often \\
\hline & Poor / vague brief by client & Sometimes \\
\hline & $\begin{array}{l}\text { Inadequate time provision to prepare tender } \\
\text { documents }\end{array}$ & Sometimes \\
\hline \multirow{7}{*}{$\begin{array}{l}\text { Originated by } \\
\text { Consultant }\end{array}$} & Design changes & Often \\
\hline & Defects in design & Sometimes \\
\hline & Inadequate consideration of design & Rarely \\
\hline & Incorrect assessment of brief & Rarely \\
\hline & Defects in BOQ & Often \\
\hline & $\begin{array}{l}\text { Shortcomings in contractual pricing } \\
\text { documents }\end{array}$ & Sometimes \\
\hline & Inadequate site investigation & Rarely \\
\hline \multirow{4}{*}{$\begin{array}{l}\text { Originated by } \\
\text { Unforeseeable } \\
\text { Events }\end{array}$} & Restrictions due to existing utility lines & Sometimes \\
\hline & Floods and landslides & Sometimes \\
\hline & Land acquisition problem & Often \\
\hline & Arranging funds & Often \\
\hline
\end{tabular}

According to findings, requirement increase and forced change in mind often occur leading to variations. Design changes and defects in BOQs often caused variations as being consultant originated. Shortcoming in contractual pricing documents and defects in design commonly occurred and other rest of causes rarely originated variations. Land acquisition problems and arranging funds often provide room for variations and other causes sometimes lead to variations as unforeseeable events. Further explanations for causes are discussed at a forthcoming section of this paper. Next section presents the findings on nature of variations.

\subsection{Nature of variations in highways}

Six factors which account for nature of issuing variations identified through ICTAD 2007 and FIDIC 1999 were taken into consideration to find out the nature of variations in road widening projects as in figure 1.

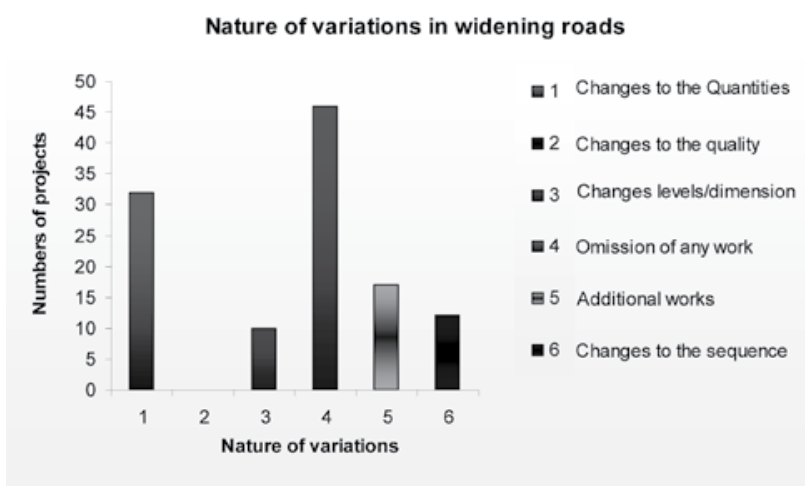

Figure 1: Nature of variations in widening roads

Accordingly, nature of variations is significant as an omission of any work. This reasoned due to problems of land acquisition and arranging funds. Although at initial stages, RDA decides to extend or widen a road it may not be fully implemented due to above mentioned reasons. Thus, projects may get suspended or significantly amended before reaching the final stag- 
es. When variations often come into account, it may increase the final contract sum. At that time, some items in original scope of work have to be deleted to manage variations within budget. During the construction stage, some materials will be required in quantities more than estimated in the $\mathrm{BOQ}$. This condition is an inevitable aspect in highways construction. This is mainly due to defects in BOQ. Apart from above, changes to sequence and levels/dimensions also occasionally occurred. However, changes to quality have not been observed in any highway project due to defined quality aspects of highway projects. All works of highways construction are carried out to some defined standards and specifications of the RDA.

\section{Nature of effects of variations on the final con- tract sum}

Figure 2 presents nature of variations in final contract sums of 58 highway projects.

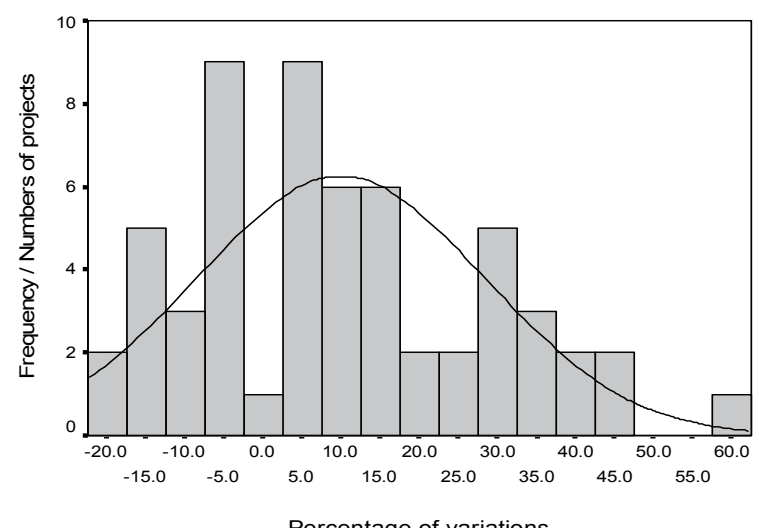

Figure 2: Percentage of variations in the final contract sum

Numbers of projects come to an end with positive variation amounts and as a result, nature of them results in cost overruns, such as changes to quantities, additional works, changes to sequence etc. Therefore, there is a high probability to occur positive percentage of variations. There was $9.9 \%$ mean of changes caused to the final contract sum by variations and on the other hand it establishes that there was $9.9 \%$ increase to the initial contract sum. However, according to literature findings, it is stated that mean of changes to initial contract sum by variations in road projects is $13 \%$. Therefore, with $95 \%$ confidence level of mean difference between analysed mean and hypothesis mean, it can be stated that variations cause a final contract sum to decrease by $3.1 \%$ of the initial contract sum. Finally, this paper presents the findings related to effects of variations.

\subsection{Effects of variations}

As mentioned above, effects of variations have been analysed according to coding structure illustrated in figure 3 .

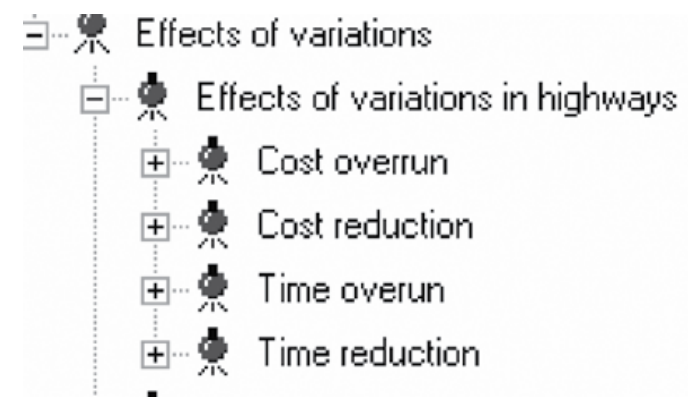

\section{Figure 3: Effects of variations}

\section{Cost overrun}

Cost overrun of a project means the actual cost increase to the client during construction period of a project. It is merely the excess of value over the originally envisaged spending for the project (contract sum stated in the letter of acceptance).

Cost overrun $=($ Final account amount - Initial contract sum $) \times 100$ Initial contract sum

In cost overrun, it consists not only of variations, but includes price escalations and day works, etc as well. However, impact of variations on the final contract sum is comparatively higher than that of other parameters which cause cost overruns. Figure 4 has been drawn for 39 projects which exceeded the cost in the final contract sum. Variation amounts and actual cost overruns for each project are present in figure 4.

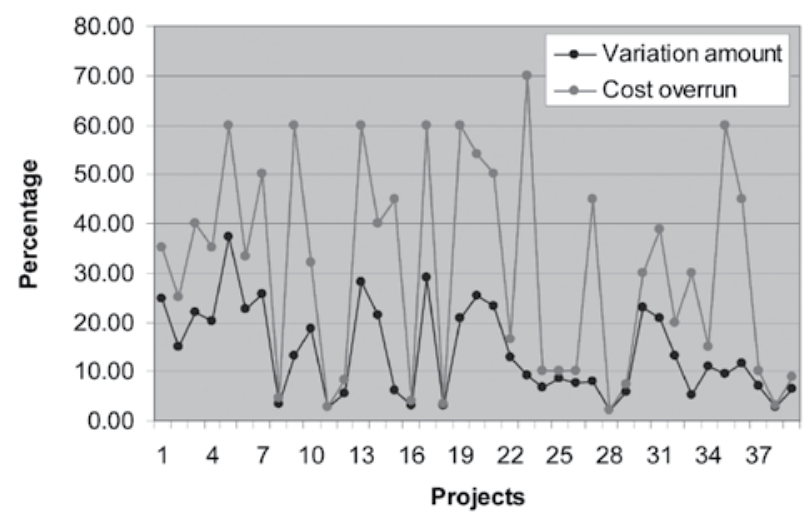

Figure 4: Deviation of variations and cost overrun in projects

Figure 4 indicates that variation amounts in lots of projects are similar or greater than half the amounts of cost overruns. Hence, it is clear that variations greatly impact on cost overruns which may incur additional costs to the client.

\section{Cost reduction}

Cost reduction of a project means that actual cost decreases and it is short of originally envisaged spending for the project.

Cost reduction $=($ Initial contract sum - final account amount $) \times 100$ Initial contract sum

Cost reductions can occur due to impact of omissions of works. Omission of works is aspect of variations which often appear in highways construction as men- 
tioned above. Omissions can result due to causes such as problems associated with land acquisition, arranging funds etc. Behaviour of cost reduction for identified 19 projects is illustrated in figure 5 .

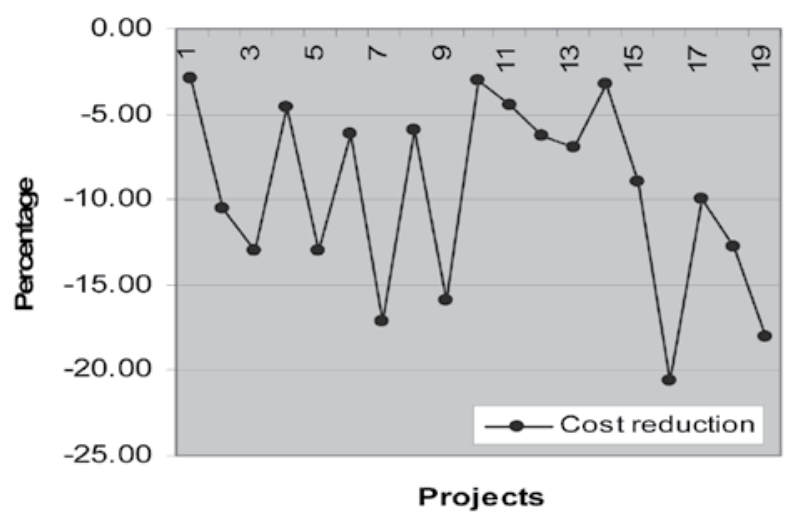

Figure 5: Cost reduction in the projects

\section{Time overrun}

Time overrun means the actual delay of construction beyond stipulated date of completion. The actual measure of time overrun means the difference between the actual construction completion period minus the planned construction completion period.

Time Overrun $=($ Actual construction period - planned construction competition period.)

It was realized that additional works, changes to sequence and levels/dimensions are aspects of variations that result in requirement of additional time to complete the works.

\section{Time reduction}

Time reduction means that actual completion of construction is before the stipulated date of completion. The actual measure of time reduction is the difference between actual completion period minus the planned completion period.

Time reduction $=($ Planned construction competition period - actual construction period) Omissions in projects result in time reduction caused by termination of projects at some unpredicted point due to reasons such as land acquisition matters, deletion of works, problem of arranging funds etc.

\subsection{Perceptions of variations}

Perceptions on variations of professionals involved in highway construction are analysed based on the following coding structure.

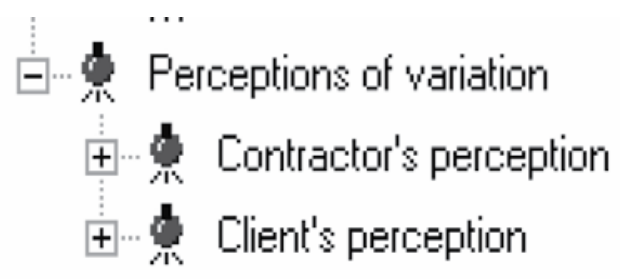

\section{Contractor's perception}

According to survey findings contractor's perception is that "variation is an unfair situation and it will always issue bad results". One reason is that when variations are issued, although rate breakdown for a new rate is submitted, RDA may not approve a new rate. They usually give priority for prevailing quoted rates. However, that may not be of benefit to a contractor than getting a new rate. When variations habitually emerge, it may affect the critical path of the master programme. Thereby, future works and current works have to be changed and it may incur additional costs to the contractor. Another problem to a contractor is that they may need various plants and equipments anticipated. Apart from that, some plant and equipment may have to be imported.

Similarly, although time extensions are approved by RDA for delay due to variations, corresponding claims may not be fully paid. Then contractors have to go into arbitration, adjudication etc. which is an additional cost as well. These are some difficulties which have to be faced by contractors due to variations. Even if RDA pays for a delay, it may not be adequate to cover loss of opportunity costs for delayed time. Omissions reduce scope of work. If there is an omission, contractor suffers a loss, because RDA is very reluctant to pay a claim on loss of profit and overheads to a contractor.

\section{Client's perception}

As per client's perception, it states that "variation is not a big issue and it will always provide support to adjust the works". Further, it indicates that prior to issuing a variation order, client will check whether funds are available or not to proceeds with it. A contractor has to execute works according to a variation order issued. Contradictory to contractor's perception, clients indicates that if a varied item relates to an already existing item in a BOQ, a new rate will not be generally approved. Furthermore, it is said that to effect client's requirements while construction work is carried out, it is more beneficial to by variations than opting for new contracts. In spite of benefits, clients indicate that reduction of scope of work (omissions) incur an additional cost to clients. Identifying plusses and minuses, client's view variations is not a big issue and it is a tool to adjust the work in construction at any time.

\section{Conclusions}

Highways play a significant role in the economy of a country. Hence, developing countries tend to develop many highways. Thereby, nowadays highway construction has increased. However, problems are beset with highwayss construction. Among those, variation is a considerable issue. In this background, this study aimed to find out causes, nature and effect of variations in highways construction. To accomplish above, a comprehensive literature review, questionnaire survey and semi-structured interviews were conducted among construction professionals involved in highway construction in Sri Lanka. 
According to survey findings, requirement increase and forced change of mind are identified as often appearing causes of client originated variations while design changes and defects in BOQ are identified as frequent causes of consultant originated variations. Under unforeseeable events, problems of land acquisition and arranging funds are identified as major causes of variations. Omissions of works and changes to quantities are identified as frequent nature of variations in highways construction. Generally, land acquisition problems and defects in BOQ are causes of aforesaid natures, respectively. Further results revealed that omission of works result in cost reduction while positive change of quantities assists cost overruns. However, findings revealed higher number of cost overrun projects than number of cost reduction projects. According to the analysis, it is identified that variations cause at least a $9.9 \%$ mean change of initial contract sum. Thus, it can be argued that effect of variations is visible in the form of cost overruns in highways construction. Clients view variations as an opportunity which always provide for convenience to adjust the works while contractors view that it is an unfair situation and will always bring in bad results.

\section{References}

Akinsola, A. and Potts, K.F., 1998. A methodology for evaluation of the variation clause in the standard forms of contract, Proceeding of COBRA 98, RICS

Arseculeratne, K.L.P.F., 1992. Nature and effects of variations in building contracts. Unpublished Dissertation (BSc). University of Moratuwa.

Bogamuwa, M.M.J.C., 2006. How Sri Lankan con tractors correct the winners curse. Unpub lished Dissertation (BSc). University of Mor atuwa.

Day, K.L., 2006. Assessing the impact of highway de velopment on land use/land cover changing in Appalachian Ohio. Thesis (MA). Ohio Uni versity.

Dorter, J. (1991) Variations. Construction Law Jour nal, 7(4), pp281-302.
Fenn, P., Lowe, D. and Speck, C. (1997).Conflict and dispute in construction. Construction Management and Economics 15: 513-518.

FIDIC., 1999. Conditions of contract for building and engineering works designed by the employ er.1st ed. International; Federation of Con sulting Engineers: Geneva.

Institute for Construction Training And Development, 2007. Standard bidding document: procure ment of works, Vol. 1, Sri Lanka: ICTAD, (ICTAD/SBD/02).

Lathem, M., 1993. Trust and Money. Interim report of the joint Government/Industry review of procurement and contractual arrangements in the United Kingdom construction Industry. HMSO: London.

Nishanth, T., 2005. Cost and time overruns in road rehabilitation projects in Sri Lanka. Unpub lished Dissertation (BSc). University of Mor atuwa.

Ogleby, C.H. and Hicks, R.G., 1982. Highway en gineering, 4th ed, John Wiley and Sons Inc: New York.

Potts, K., 2003. Risk management on variations two civil engineering case study, Proceeding of COBRA 03, RICS

Ramus, J.W. 1989, Contract practice for quantity sur veyors, 2nd ed, Heinemann Newnes.

RDA. (2009). Road development authority - Sri Lan ka [online]. Available from: http://www.rda. gov.lk/ [ Accessed 22 Aug 2009].

Sutrisna, M. and Potts, K. (2004), Using Multiple Decision-Makers for Valuing Variations in Civil Engineering Works. In: 3rd Scientific Conference on Project Management. Thes saloniki, 23-24 September.

Sutrisna, M., Potts, K. \& Proverbs, D.(2003). A Novel Approach Towards Decision-Making in the Valuation of Variations. In: 2nd Interna tional Conference on Innovation in Architec ture, Engineering and Construction. Lough borough, 25-27 June 2003. Anumba, C. (Editor). Rotterdam: Millpress, pp. 431-440. 